Vol 1. No 2. November 2021, e-ISSN : 2807-1670 | p-ISSN : 2807-2316

\title{
PENINGKATAN KEMAMPUAN MENULIS NASKAH PIDATO PERSUASIF MENGGUNAKAN PUEBI SISWA KELAS IX SMPN 1 SANGA DESA KABUPATEN MUSI BANYUASIN
}

\section{ELPHILIA}

SMP Negeri 1 Sanga Desa Muba Sumsel

Email : elphiliasaroli@gmail.com

\begin{abstract}
ABSTRAK
Penelitian ini bertujuan untuk meningkatkan kemampuan menulis naskah pidato persuasif menggunakan pedoman umum ejaan bahasa Indonesia (PUEBI) yang meliputi (tanda baca, huruf kapital, dan kata penghubung) siswa kelas IX SMP Negeri 1 Sanga Desa. Penelitian ini merupakan penelitian tindakan kelas yang terdiri dari dua siklus yang setiap siklus terdiri dari empat tahapan. Siklus pertama dan siklus kedua masing-masing dilaksanakan dua kali pertemuan. Hasil dan pembahasan menulis naskah pidato persuasif menggunakan pedoman umum ejaan bahasa Indonesia yang meliputi (tanda baca, huruf kapital, dan kata penghubung) dapat meningkatkan hasil belajar siswa kelas IX SMP Negeri 1 Sanga Desa. Berdasarkan hasil penelitian dari jumlah 27 siswa, 15 siswa yang berhasil mencapai KKM, 12 siswa belum mencapai KKM sehingga persentase ketuntasan yang diperoleh sebesar 55,55\%. Nilai rata-rata yang diperoleh yaitu 63,26. Pada siklus kedua dari jumlah 27 siswa, 22 siswa yang berhasil mencapai KKM, 5 siswa belum mencapai KKM sehingga persentase ketuntasan yang diperoleh sebesar $81,48 \%$. Nilai rata-rata yang diperoleh siswa yaitu 72,55. Jadi, berdasarkan hasil penelitian menulis naskah pidato persuasif menggunakan pedoman umum ejaan bahasa Indonesia yang meliputi (tanda baca, huruf kapital, dan kata penghubung) mengalami peningkatan.
\end{abstract}

Kata kunci: Menulis, Pidato Persuasif, dan PUEBI

\section{ABSTRACT}

This study aims to improve the ability to write persuasive speeches using general Indonesian spelling guidelines (PUEBI) which include (punctuation, capital letters, and conjunctions) grade IX students of SMP Negeri 1 Sanga Desa. This research is a classroom action research which consists of two cycles, each cycle consists of four stages. The first and second cycles were held in two meetings each. The results and discussion of writing persuasive speeches using general Indonesian spelling guidelines which include (punctuation, capital letters, and conjunctions) can improve the learning outcomes of class IX students of SMP Negeri 1 Sanga Desa. Based on the results of the study of the number of 27 students, 15 students who managed to reach the KKM, 12 students have not reached the KKM so that the percentage of completeness obtained is $55.55 \%$. The average value obtained is 63.26 . In the second cycle of the number of 27 students, 22 students who managed to reach the KKM, 5 students have not reached the KKM so that the percentage of completeness obtained is $81.48 \%$. The average value obtained by students is 72.55 . So, based on the research results, writing persuasive speeches using general Indonesian spelling guidelines which include (punctuation, capital letters, and conjunctions) has increased.

Keywords: Writing, Persuasive Speech, and PUEBI

\section{PENDAHULUAN}

Menurut Kamus Besar Bahasa Indonesia (2018:1785), menulis yaitu melahirkan pikiran dan perasaan (seperti mengarang, membuat surat) dengan menggunakan tulisan. Menulis artinya mengemukakan isi hati penulis dalam bentuk tulisan, sehingga maksud hati penulis dapat diketahui banyak orang melalui tulisan tersebut. Kemampuan seseorang dalam menyampaikan tulisannya berbeda-beda sesuai dengan kompetensi masing-masing. 
Menulis merupakan buah pikiran, gagasan, perasaan, serta keinginan penulis agar dapat dipahami oleh pembaca dalam bentuk tulisan dengan tujuan hal yang ditulis oleh penulis dapat menghibur, menginformasi, meyakinkan, dan dapat mengekspresikan perasaan yang kuat serta bersemangat.

Menulis merupakan salah satu keterampilan berbahasa. Kegiatan menulis sangat diperlukan oleh peserta didik khususnya, karena berguna untuk kepentingan pengembangan diri. Hal ini berguna untuk peserta didik tersebut melanjutkan pendidikan yang lebih tinggi dan bisa digunakan nanti di masyarakat. Kegiatan menulis naskah pidato, hal yang sangat bermanfaat bagi seseorang. Apalagi bagi peserta didik.

Tim Edukatif (2016:40) mengemukakan pidato suatu keterampilan berbicara menginformasikan hal atau buah pikiran di masyarakat. Pidato persuasif adalah pidato yang bersifat mempengaruhi pendengar melalui ide-ide, saran, pendapat yang logis, jelas, dan dipertanggungjawabkan. Menurut Ekawati (2017:30) mengemukakan pidato yaitu suatu keterampilan berbicara untuk menyampaikan komunikasi buah pikiran, ide-ide, pendapat, saran atau pesan di masyarakat. Pidato persuasif adalah pidato yang isinya membujuk pendengar agar mengikuti apa yang disampaikannya. Selain itu, Trianto dkk. (2018:34) mengemukakan pidato persuasif yaitu pidato yang berupa seni seseorang dalam menyampaikan opininya yang masuk akal di depan umum.

Berdasarkan pendapat di atas, pidato persuasif adalah pidato yang berupa seni seseorang dalam menyampaikan opininya dan bersifat mempengaruhi pendengar melalui ide-ide, saran, pendapat yang logis, jelas, dan dipertanggungjawabkan di depan umum. Akan tetapi, keterampilan menulis naskah pidato harus juga memperhatikan pedoman umum ejaan bahasa Indonseia (PUEBI).

Menteri Pendidikan dan Kebudayaan dengan surat keputusan No. 196/1975 memberlakukan "Pedoman Umum Ejaan Bahasa Indonesia yang Disempurnakan dan Pedoman Pembentukan Istilah" hingga sampai tahun 2015, EYD kembali disempurnakan oleh Badan Pengembangan dan Pembinaan Bahasa, Kementerian Pendidikan dan Kebudayaan, lalu menghasilkan naskah yang telah ditetapkan menjadi Peraturan Kementerian Pendidikan dan Kebudayaan, lalu menghasilkan naskah yang telah ditetapkan menjadi Peraturan Kementerian Pendidikan dan Kebudayaan No. 50 tahun 2015 tentang Pedoman Umum Ejaan Bahasa Indonesia (PUEBI).

Proses pembelajaran menggunakan PUEBI dalam menulis naskah pidato khususnya di kelas IX SMPN 1 Sanga Desa diberikan hanya pada bagian kebahasaan, dikarenakan proses pembelajaran Bahasa Indonesia mengacu kepada silabus dan Rencana Pelaksanaan Pembelajaran (RPP). Hal ini memberikan dampak pada materi menggunakan PUEBI dalam menulis naskah pidato siswa kurang maksimal. Terbukti dari hasil proses pembelajaran menggunakan PUEBI dalam menulis naskah pidato siswa yang telah mencapai ketuntasan belajarnya sebesar $37 \%$ atau sebanyak 10 siswa, sedangkan belum mencapai hasil yang diharapkan sebesar 63\% atau sebanyak 17 siswa. Berdasarkan hasil tersebut, ada beberapa faktor yang menyebabkan kemampuan siswa dalam menulis naskah pidato menggunakan PUEBI tidak mencapai ketuntasan dalam belajar adalah sebagai berikut.

1. Materi pokok bahasan menggunakan PUEBI dalam menulis naskah pidato siswa hanya bagian dari pokok kebahasaan pidato dan dirasakan kurang maksimal.

2. Siswa kurang memahami dalam penggunaan PUEBI yang benar sesuai kaidah tersebut.

3. Pembelajaran yang diberikan khusus mengenai PUEBI sangat sedikit.

4. Kebiasaan siswa menggunakan kesalahan PUEBI dalam menulis.

5. Kurangnya minat siswa untuk membaca buku PUEBI.

6. Adanya perbedaan transfer yang diterima dari pengajaran berbahasa di sekolah maupun di rumah.

Berdasarkan uraian beberapa faktor yang menyebabkan hasil belajar siswa menulis naskah pidato menggunakan PUEBI tidak mencapai ketuntasan dalam belajar, penulis merasa 
perlu untuk mengembangkan proses pembelajaran menulis naskah pidato menggunakan PUEBI.

\section{METODE PENELITIAN}

Penelitian ini dilaksanakan di SMP Negeri 1 Sanga Desa. Subjek penelitiannya adalah siswa kelas IX SMP Negeri 1 Sanga Desa mengenai Peningkatan Kemampuan Menulis Naskah Pidato Persuasif Menggunakan PUEBI. Waktu dan lamanya tindakan dalam penelitian ini diperkirakan Juli 2021 sampai dengan Oktober 2021. Penelitian ini berupa penelitian tindakan kelas yang dilakukan dua siklus. Dalam setiap siklus terdapat tahap-tahap penelitian. Menurut Sulipan (dalam Hamdani dan Dody Hermana, 2008:52) mengemukakan tahapan PTK ada 4 tahapan sebagai berikut yaitu (1) perencanaan tindakan, (2) pelaksanaan tindakan, (3) pengamatan tindakan, (4) refleksi terhadap tindakan. Siklus tahap-tahap penelitian tindakan kelas dapat dilihat pada gambar berikut.

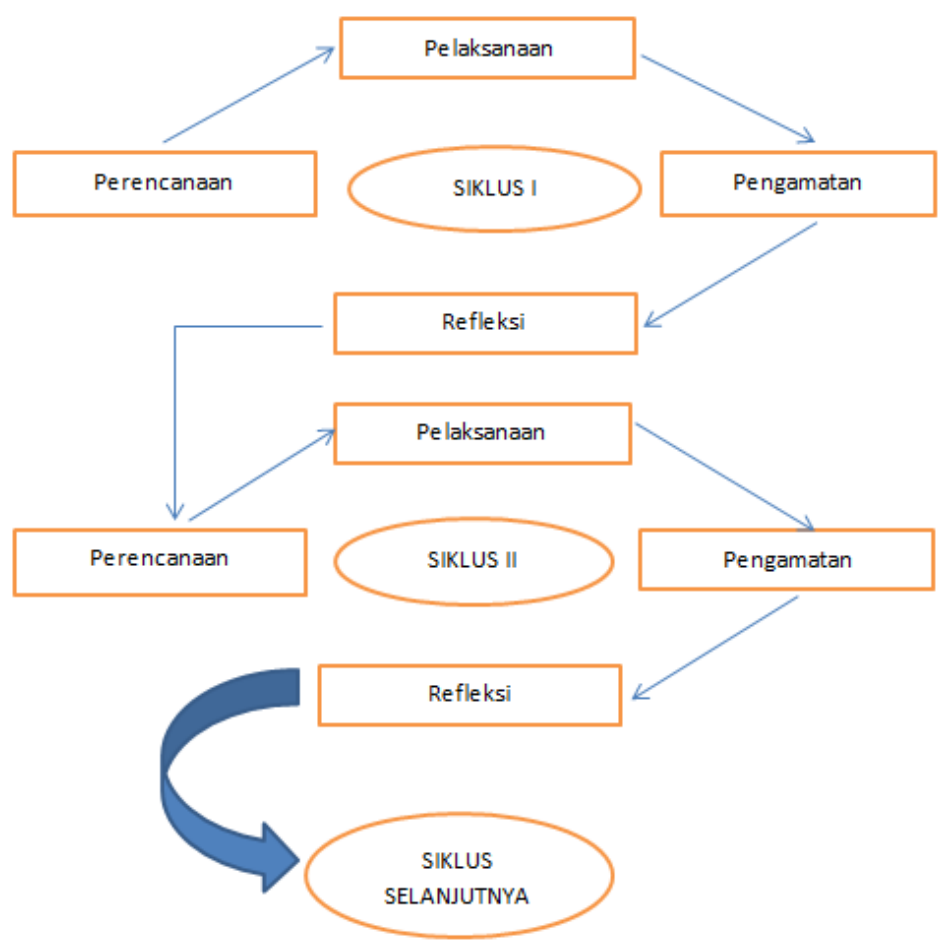

Gambar 1. Siklus Penelitian Tindakan

(Hamdani dan Dody Hermana, 2008:52)

\section{HASIL DAN PEMBAHASAN}

\section{Siklus Pertama}

Berdasarkan hasil pelaksanaan siklus pertama pembelajaran menggunakan pedoman umum ejaan bahasa Indonesia yang meliputi (tanda baca, huruf kapital, dan kata penhubung) dalam menulis naskah pidato persuasif kelas IX SMP Negeri 1 Sanga Desa diperoleh penilaian tes hasil belajar yang telah dilakukan. Hasil yang didapatkan siswa mengalami peningkatan dibandingkan dengan hasil pada pra siklus. Berikut ini rekapitulasi penilaian hasil belajar siswa pada siklus pertama,

Tabel 1. Rekapitulasi Penilaian Hasil Belajar Siklus 1 Menulis Naskah Pidato Persuasif Menggunakan PUEBI

\begin{tabular}{|c|c|c|}
\hline No. & Uraian & Hasil Siswa \\
\hline 1 & Nilai Rata-Rata & 63,26 \\
\hline 2 & Nilai Tertinggi & 80 \\
\hline
\end{tabular}




\begin{tabular}{|l|c|c|}
\hline 3 & Nilai Terendah & 40 \\
\hline 4 & Jumlah Siswa yang Tuntas & 15 \\
\hline 5 & Jumlah Siswa yang Tidak Tuntas & 12 \\
\hline 6 & Persentase Ketuntasan & $55,55 \%$ \\
\hline
\end{tabular}

Dari data di atas dapat diketahui bahwa pembelajaran menulis naskah pidato persuasif menggunakan pedoman umum ejaan bahasa Indonesia yang meliputi (tanda baca, huruf kapital, kata penghubung) kelas IX SMP Negeri 1 Sanga Desa diperoleh nilai rata-rata 63,26. Dari 27 siswa, sebanyak 15 siswa yang tuntas, dan 12 siswa yang tidak tuntas karena nilai yang diperoleh belum mencapai KKM yang diharapkan. Nilai KKM yang ditetapkan sekolah 65, tetapi persentase ketuntansan siswa 55,55\%. Hal ini masih kurang dari kriteria ketuntasan minimum yang diharapkan.

Berdasarkan hasil data di atas, perlu adanya tindakan perbaikan dalam pembelajaran melalui pembelajaran menggunakan pedoman umum ejaan bahasa Indonesia yang meliputi (tanda baca, huruf kapital, kata penghubung) sehingga diharapkan hasil belajar siswa menulis naskah pidato persuasif dapat meningkat.

\section{Siklus Kedua}

Dari hasil pelaksanaan siklus kedua diperoleh hasil penilaian tes hasil belajar yang telah dilakukan. Hasil yang didapatkan siswa mengalami peningkatan dibandingkan dengan hasil pada siklus pertama. Berikut hasil rekapitulasi penilaian hasil belajar siswa pada siklus kedua.

Tabel 2. Rekapitulasi Penilaian Hasil Belajar Siklus 2 Menulis Naskah Pidato Persuasif Menggunakan PUEBI

\begin{tabular}{|c|c|c|}
\hline No. & Uraian & Hasil Siswa \\
\hline 1 & Nilai Rata-Rata & 72,55 \\
\hline 2 & Nilai Tertinggi & 90 \\
\hline 3 & Nilai Terendah & 50 \\
\hline 4 & Jumlah Siswa yang Tuntas & 22 \\
\hline 5 & Jumlah Siswa yang Tidak Tuntas & 5 \\
\hline 6 & Persentase Ketuntasan & 81,48 \\
\hline
\end{tabular}

Dari data di atas, dapat diketahui bahwa pembelajaran menulis naskah pidato persuasif menggunakan pedoman umum ejaan bahasa Indonesia yang meliputi (tanda baca, huruf kapital, kata penghubung) kelas IX SMP Negeri 1 Sanga Desa pada siklus kedua diperoleh nilai ratarata 72,55. Dari 27 siswa, sebanyak 5 siswa yang tidak tuntas karena nilai yang diperoleh belum mencapai KKM yang diharapkan. Siswa yang telah mencapai KKM sebanyak 22 siswa. Nilai KKM yang ditetapkan sekolah 65. Persentase ketuntansan siswa 81,48\%. Jadi, dapat dikatakan hasil nilai siswa sudah banyak mengalami ketuntasan karena nilai yang diperoleh siswa sesuai dengan KKM yang ditentukan sekolah.

Adapun perbandingan nilai hasil rata-rata kemampuan menulis naskah pidato persuasif menggunakan pedoman umum ejaan bahasa Indonesia yang meliputi (tanda baca, huruf kapital, dan kata penghubung) pada siklus pertama dan siklus kedua secara umum dapat dilihat pada diagram berikut. 


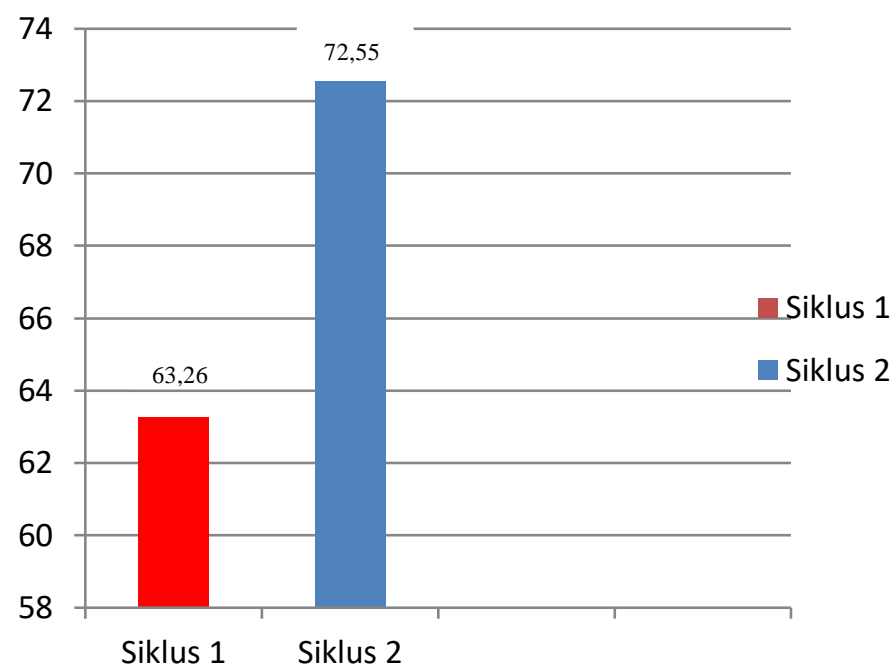

\section{Gambar 1. Nilai Rata-rata Kemampuan Menulis Naskah Pidato Persuasif Menggunakan PUEBI pada Siklus Pertama dan Siklus Kedua}

Berdasarkan diagram di atas, dapat disimpulkan bahwa kemampuan menulis naskah pidato persuasif menggunakan pedoman umum ejaan bahasa Indonesia yang meliputi (tanda baca, huruf kapital, dan kata penghubung) pada siklus pertama nilai rata-rata mencapai 63,26, lalu mengalami peningkatan pada siklus kedua dengan nilai rata-rata yaitu 72,55.

Siswa cenderung melakukan kesalahan berbahasa, seperti penulisan huruf kapital dan kesalahan tanda baca yang terdiri dari kesalahan tanda titik, tanda koma, dan tanda hubung (Melia, 2019). Keterampilan dalam menulis teks biografi siswa terdapat hubungan yang signifikan antara penguasaan pedoman umum ejaan bahasa Indonesia (PUEBI) dengan keterampilan menulis teks biografi (Wahyuni, 2021). Kesalahan penulisan huruf kapital pada karangan narasi menggunakan pedoman umum ejaan bahasa Indonesia (PUEBI) masih dilakukan siswa. Upaya yang dilakukan guru terkait dengan kemampuan siswa dalam menulis karangan adalah dengan sering memberikan tugas untuk menulis (Khasanah dkk., 2020). Melalui diskusi, guru mengemukakan berbagai persoalan atau problematika yang berkaitan dengan penggunaan ejaan, di antaranya penggunaan huruf kapital dalam penulisan subjudul, penggunaan tanda baca, penulisan kata depan, kata majemuk, penggunaan, membedakan satuan kata dan partikel (Tugiati, 2019). Beberapa kesalahan ejaan yang sering dilakukan yaitu penggunaan huruf kapital dan miring, penggunaan kata depan (di, ke, dan antar), penggunaan tanda baca, dan kata serapan (Leksono, 2019).

Untuk mengatasi kesulitan dalam kegiatan menulis tersebut, disimpulkan bahwa penggunaan Pedoman Umum Ejaan Bahasa Indonesia (PUEBI) dapat memotivasi siswa agar menulis naskah pidato persuasif sesuai dengan Pedoman Umum Ejaan Bahasa Indonesia yang sesuai kaidah.

\section{KESIMPULAN}

Berdasarkan hasil penelitian dan pembahasan, dapat disimpulkan bahwa menulis naskah pidato persuasif menggunakan pedoman umum ejaan bahasa Indonesia yang meliputi (tanda baca, huruf kapital, dan kata penghubung) kelas IX SMP Negeri 1 Sanga Desa meningkat.

Hal ini berdasarkan hasil pembahasan menyatakan bahwa pada siklus pertama dari jumlah 27 siswa yang mencapai nilai ketuntasan 15 siswa, dan yang belum mencapai ketuntasan sebanyak 12 siswa. Persentase ketuntasan pada siklus pertama 55,55\% dengan rata-rata 63,26. Kemudian, pada siklus kedua mengalami peningkatan yang mana diketahui dari jumlah 27 siswa, yang mencapai nilai ketuntasan sebanyak 22, siswa yang belum mencapai ketuntasan sebanyak 5 siswa. Persentase ketuntansan siswa pada siklus kedua 81,48\% dengan Rata-rata 
72,55. Jadi, berdasarkan data tersebut menulis naskah pidato persuasif menggunakan pedoman umum ejaan bahasa Indonesia yang meliputi (tanda baca, huruf kapital, dan kata penghubung) mengalami peningkatan dari siklus pertama ke siklus kedua pada siswa kelas IX SMP Negeri 1 Sanga Desa.

\section{DAFTAR PUSTAKA}

Badan Pengembangan dan Pembina Bahasa. 2018. Kamus Besar Bahasa Indonesia. Jakarta: CV Adi Perkasa.

Ekawati, E.B. Devitta dan Siti Isnatun M.. 2017. Bahasa Indonesia SMP/MTs Kelas IX. Bogor: Yudhistira.

Hamdani, Nizar Alam dan Dody Hermana. 2008. Classroom Action Research Teknik Penulisan dan Contoh Proposal PTK. Garut Jawa Barat: Rahayasa.

Khasanah. Rohma Uswatun dkk. 2020. Analisis Kesalahan Penulisan Huruf Kapital Pada Karangan Narasi Menggunakan Pedoman Umum Ejaan Bahasa Indonesia (PUEBI). Purwokerto: Jurnal IKA: Ikatan Alumni PGSD UNARS Vol. 1 No. 6, Juni 2020.

Leksono, M. Lukman. 2019. Analisis Kesalahan Penggunaan Pedoman Ejaan Bahasa Indonesia (PUEBI) Pada Tugas Makalah dan Laporan Praktikum Mahasiswa IT Telkom Purwokerto. Jurnal Pendidikan Bahasa dan Sastra Indonesia Volume 4 Nomor 2 September 2019.

Melia. 2019. Analisis Tata Tulis Karangan Eksposisi Kelas X IPS SMK Muhammadiyah Pontianak (Ditinjau Berdasarkan PUEBI). Pontianak. Edukasi: Jurnal Pendidikan, Vol. 17, No. 1, Juni 2019. Hal. 90-97.

Tim Edukatif. 2016. Mahir Berbahasa Indonesia SMP/MTs Kelas IX. Jakarta: Erlangga.

Trianto, Agus dkk.. 2018. Bahasa Indonesia SMP/MTs Kelas IX. Jakarta: Kementerian Pendidikan dan Kebudayaan.

Tugiati, Tutut dan Kuntoro. 2019. Penggunaan Ejaan Bahasa Indonesia sesuai PUEBI Untuk Kepentingan Penulisan Perangkat Pembelajaran. Purwokerto. Seminar Nasional Hasil Penelitian dan Pengabdian Pada Masyarakat IV.

Wahyuni, Neneng dan Wirda Linda. 2021. Penguasaan PUEBI dan Keterkaitannya dengan Keterampilan Menulis Teks Biografi Siswa SMA. Kecamatan Lareh Sago Halaban. Literatur: Jurnal Bahasa, Sastra dan Pengajaran Volume 1, Nomor 2. 